Original Article

\title{
Range of motion, muscle length, and balance performance in older adults with normal, pronated, and supinated feet
}

\author{
Maria Justine, PT, PhD ${ }^{1)^{*}}$, Dhiya Ruzali, PT, BPT ${ }^{1)}$, Ezzaty Hazidin, PT, BPT ${ }^{1)}$, \\ Aisyah Said, PT, BPT ${ }^{1)}$, SAiful Adli Bukry, PT, MPT ${ }^{1)}$, Haidzir Manaf, PT, PhD $^{1)}$ \\ 1) Department of Physiotherapy, Universiti Teknologi MARA: Puncak Alam Campus, 42300 Puncak \\ Alam, Selangor, Malaysia
}

\begin{abstract}
Purpose] To compare the lower limb joint range of motion and muscle length between different types of foot posture, and determine the correlation of range of motion and muscle length with balance performance. [Subjects and Methods] Ninety individuals (age, 65.2 \pm 4.6 years) were assessed using the Foot Posture Index to determine their type of foot (Normal [ 0 to +5$]$, pronated [ +6 to +9 ], and supinated [ -1 to -4$] ; n=30$ per group). The range of motion (goniometer), muscle length (goniometer and tape measure), and balance performance (functional reach test and four square step test) were measured for each participant. Data were analyzed using the KruskalWallis test and Spearman's rank-order correlation. [Results] No significant differences were found in range of motion, muscle length, and balance performance among different types of foot posture, except for right and left ankle dorsiflexion range of motion. Balance performance was significantly correlated with selected muscle length and range of motion, especially in the supinated foot. [Conclusion] Range of motion and muscle length of the lower limb may be associated with balance performance in older adults with foot deformities. These findings may guide physiotherapists in choosing intervention based on specific assessments for older adults with foot deformity. Key words: Foot posture, Balance performance, Older adults
\end{abstract}

(This article was submitted Oct. 23, 2015, and was accepted Dec. 12, 2015)

\section{INTRODUCTION}

The foot plays an essential role in human movement, as it is the only part of the body that provides contact with the supporting surface during weight bearing activities such as standing, walking, hopping, jumping, and running. It is responsible for absorbing shock, adapting to irregular surfaces, and generating momentum for forward propulsion during gait ${ }^{1)}$. Unfortunately, any changes to the foot posture may eventually impair its function and make it prone to injury during physical activities $^{2}$.

In older adults, changes in the foot structure may be related to the wear and tear processes that progress over the years. For instance, due to the normal aging process, muscle properties decline about $30-50 \%$ between the ages of 40 and 80 years old; this decline may result in reduced range of motion (ROM), reduced muscle strength, and diminished plantar tactile sensation leading to alteration in plantar loading responses ${ }^{3)}$. These changes may affect the foot posture and, in turn, limit its ability to withstand any perturbation to balance control.

Generally, there are three types of foot posture: neutral or normal, pronated, and supinated. The neutral foot has a normal anatomical structure with strong ligaments and normal height of one transverse and two longitudinal arches, providing a better postural stability. The pronated foot presents with flattening of the medial arch, calcaneal eversion, forefoot valgus, and a hypermobile midfoot ${ }^{4}$. As a result of this posture, the head of the talus is displaced medially and posteriorly from the

\footnotetext{
*Corresponding author. Maria Justine (E-mail: maria205@salam.uitm.edu.my)

(C)2016 The Society of Physical Therapy Science. Published by IPEC Inc.

This is an open-access article distributed under the terms of the Creative Commons Attribution Non-Commercial No Derivatives (by-nc-nd) License $<$ http://creativecommons.org/licenses/by-nc-nd/4.0/>.
} 
navicular ${ }^{5)}$. These alterations may stretch the spring ligament and tendon of the tibialis posterior muscle, potentially leading to increased dropping of the medial longitudinal arch (MLA) and greater demand on the neuromuscular system to stabilize the foot and maintain an upright stance. However, the pronated foot is able to unlock the mid-tarsal region during ambulation due to its loose-packed characteristics, allowing it to act as a shock absorber. A study has shown that a pronated foot may eventually cause mechanical problems at the waist, hip, and knee joints including excessive calcaneal extroversion of about 2 to 3 degrees $^{6}$ ) that may further lead to overuse injury ${ }^{7}$. In contrast, the supinated foot, which is also known as a high-arched foot, presents with excessively high MLA, calcaneal inversion, and forefoot varus. The supinated foot is vulnerable as it may not adequately adapt to the underlying surface, increasing the demand on the surrounding musculoskeletal structures to maintain postural stability and balance due to its hypomobile midfoot ${ }^{4}$. As a result, it may not be able to distribute the weight bearing evenly along the metatarsal heads and lateral side of the foot ${ }^{5}$, exposing it to decreased plantar sensory input and a significantly larger center of pressure excursion than other foot postures ${ }^{8)}$. However, unlike the pronated foot, the supinated foot may provide a rigid lever for propulsion but is not efficient as a shock absorber. Previous studies have reported that 23 to $60 \%$ of subjects with a supinated foot experienced foot pain ${ }^{9,10)}$. Among athletes with high-arched feet, increased arch height was associated with decreased mediolateral control of single-limb stance ${ }^{11}$, potentially increasing the risk of lower limb injury.

Both the supinated and pronated foot are at a greater mechanical disadvantage than a neutral foot, especially for maintaining balance while performing activities in weight bearing. The aim of this study was to compare the lower limb joint ROM of the hip, knee, and ankle joints and lower limb muscle length (ML) of the hamstrings, quadriceps, gastrocnemius, and soleus between different types of foot postures (normal, pronated, and supinated) in older adults. Additionally, this study also aimed to determine the correlation of ROM and ML with balance performance.

\section{SUBJECTS AND METHODS}

A total of 90 community-dwelling older women aged 60 years and above were recruited for this cross-sectional study. The Gpower 3 software was used to calculate the sample size, and indicated that 26 participants were sufficient to detect an effect size of $80 \%$ power and alpha of 0.05 . Anticipating a patient withdrawal rate of 20 to $30 \%$ during assessment, the sample size was increased to 30 per group. The participants were divided into three different groups based on their foot posture using the foot posture index (FPI): normal foot $(n=30)$, pronated foot $(n=30)$, and supinated foot $(n=30)$. Participants were included in the study if they met these criteria: community-dwelling, aged 60 years old or above, and able to walk about 10 meters without using walking aids. Meanwhile, the participants were excluded if they presented with other foot symptoms such as pain, swelling, or loss of sensation; BMI more than $30 \mathrm{~kg} / \mathrm{m}^{2}$; a chronic orthopedic condition such as rheumatoid arthritis (RA) or severe osteoarthritis (OA) pain in the lower limb or fracture; a vestibular problem; or visual or peripheral sense disturbances. The ethics approval was obtained from the University's Research Ethics Committee, and all participants signed written informed consents.

Participant details such as age (year), body weight $(\mathrm{kg})$, and height $(\mathrm{m})$ were recorded. The body weight and height were used to calculate the body mass index (BMI; $\mathrm{kg} / \mathrm{m}^{2}$ ) for each participant. All measurements were performed by three research assistants who were graduates of the physiotherapy degree program.

The FPI was used to classify the participants' foot postures using a six clinical criteria ${ }^{12}$. The participants were required to stand with both feet shoulder width apart while the assessor observed their foot from the frontal plane, sagittal plane, and posterior aspect. The FPI six scoring system includes the following six components: palpation of the talar head, palpation of the supra- and infra-lateral malleolar curvature, calcaneal frontal plane position, prominence in the region of the talonavicular joint, congruence of the MLA, and abduction or adduction of the forefoot on the rearfoot. Each component score ranged from -2 to +2 . The summation of the scores obtained was calculated to classify the participants into their respective groups (Normal [ 0 to +5$]$, pronated [ +6 to +9 ], and supinated [ -1 to -4$]$ ). The researcher chose to use the FPI as this index is able to evaluate the foot in various planes and has been shown to be valid in various clinical settings ${ }^{13)}$. The FPI was developed to provide better foot measurements ${ }^{12)}$ due to the lack of validated methods to categorize or quantify variations in foot postures in the clinical area ${ }^{2}$.

The measurements of joint ROM were taken using a standard goniometer at the lower limb joints including the hip (flexion, extension), knee (flexion, extension), and ankle (plantarflexion, dorsiflexion, inversion, eversion) joints. The procedure for measuring the joint ROM followed the protocol recommended by Clarkson ${ }^{14)}$. Both sides of the limb were measured, each measurement was performed three times, and the average score was recorded for analysis. Higher scores corresponded to a larger range of motion.

Muscle length measurements were taken from the major muscles of the lower limb including the hamstrings, quadriceps, gastrocnemius, and soleus. All measurements followed the procedures described by Bandy and Reese ${ }^{15)}$. The hamstring length was determined by measuring the straight-leg raise using a goniometer. The quadriceps length was determined by measuring the quadriceps femoris muscle angle during passive knee flexion with the subject in the prone position. The gastrocnemius and soleus ML were measured with the patient in the prone position with the knee straight and the knee flexed $\left(90^{\circ}\right)$, respectively. Both sides of the muscles were measured three times each, and the average was recorded as the final score. 
Balance performance was measured using the functional reach test (FRT) ${ }^{16}$. The researchers chose the FRT as it demonstrates the maximal distance a person can reach forward beyond arm's length while maintaining a fixed based of support in standing position; the FRT also serves as an index of fall risk ${ }^{17)}$. Participants were instructed to stand with their feet shoulder distance apart, make a fist, and raise their arm to be parallel with the floor. The assessor took an initial reading on the yardstick, using the knuckle of the third metacarpal as the landmark. The participants were instructed to reach forward along the yardstick without moving their feet. The assessor took a reading on the yardstick of the farthest reach attained by the participant without taking a step. The initial reading was subtracted from the final to obtain the FRT score. A score of less than six inches indicates a balance limitation, while a score of more than 10 inches indicates adequate balance for older adults.

The four square step test (FSST) was also used to measure balance performance; this test assesses the participants' ability to step over objects forward, sideways, and backwards ${ }^{18}$. We suggest that the FSST is more challenging than the FRT, as the FSST requires the participants to lift up the leg and coordinate their movements as fast as possible. The participants were instructed to step over four canes setup like a cross on the floor with the tips of the canes facing together. At the start of the test, the participants stood on the upper left square (in square one and facing square two). Then the participants started stepping in a clockwise pattern as follows: square one, square two, square four, square three, and finally returning to square one with both feet. Next, participants continued stepping counter-clockwise in the following pattern: square three, square four, square two, and ending in square one with both feet. The assessor demonstrated the procedure once and allowed the participants to perform one practice trial prior to administering the test. The participants performed two trials, and the better time (measured in seconds) was taken as the score.

Data analysis was performed using the SPSS 20.0 software. Descriptive analysis was conducted to determine the means, standard deviations, and $\mathrm{p}$ values for age and body mass index. The normality test indicated that all variables of interest were not normally distributed; thus, the non-parametric tests were used for further analysis. The Kruskal-Wallis test was used to compare the mean ranks for each variable. The correlation analysis was done to measure strength of relationship between ROM, ML, and dynamic balance among the three different types of foot posture. The significance level was set at $\mathrm{p}<0.05$.

\section{RESULTS}

Ninety participants completed the study, and each group was comprised of 30 subjects. There were no significant differences in age $(\mathrm{p}>0.05)$ between the normal $(65.2 \pm 4.6$ years $)$, pronated $(66.3 \pm 4.5$ years $)$, and supinated $(67.9 \pm 5.7$ years $)$ foot groups. Similarly for body mass index, no significant differences were found between the normal $\left(25.9 \pm 3.9 \mathrm{~kg} / \mathrm{m}^{2}\right)$, pronated $\left(23.7 \pm 6.6 \mathrm{~kg} / \mathrm{m}^{2}\right)$, supinated $\left(24.9 \pm 2.8 \mathrm{~kg} / \mathrm{m}^{2}\right)$ foot $\operatorname{groups}(\mathrm{F}=1.2, \mathrm{p}>0.05)$.

The mean rank comparisons for ROM, ML, and balance performance for all types of foot posture are shown in Table 1 . In terms of ROM, the only variables that showed a significant difference were the right and left ankle dorsiflexion with the most limited ROM measured in the supinated foot $(\mathrm{p}<0.05)$. There were no significant differences found between the hip, knee, ankle plantar flexion, ankle inversion, and ankle eversion ROM among different types of foot posture. Similarly for ML and balance performance (FSST and FRT), there were no significant differences among the foot posture groups (all $\mathrm{p}>0.05$ ).

The results of the relationships between ROM, ML, and balance performance are shown in Table 2. For the normal foot, the FRT was significantly correlated with the ROM of right and left hip extension as well as right and left knee extension; the FSST was significantly correlated with the ROM of right ankle plantarflexion and the ML of the right and left hamstring (all $\mathrm{p}<0.05$ ).

For the pronated foot, the FRT was significantly correlated with the ML of the left quadriceps; the FSST was significantly correlated with the ROM of right knee extension, right and left ankle dorsiflexion, and the right quadriceps ML (all p $<0.05$ ).

In the supinated foot, FRT was significantly correlated with the ROM of right and left ankle dorsiflexion, right and left ankle inversion, right and left ankle eversion, and the ML of the right and left gastrocnemius; FSST was significantly correlated with the ML of left gastrocnemius (all $\mathrm{p}<0.05)$.

\section{DISCUSSION}

Previous studies have shown that an excessively pronated foot ${ }^{19)}$ or a highly supinated foot ${ }^{8)}$ may alter standing balance in healthy young adults, but limited evidence has been reported regarding whether similar findings exist for older adults. Therefore, in this study, we present a few interesting results on range of motion, muscle length, and balance performance in older adults with different types of foot posture. Uniquely, in this study we used the FPI to reliably identify the participants' foot posture. Previously, Menz et al. ${ }^{20)}$, have used the FPI in their study on foot and ankle characteristics associated with impaired balance and functional ability in older adults. However, in the current study we used the FRT and FSST as the measures for balance performance.

The most striking result to emerge from the data is that participants with a supinated foot had limited ankle dorsiflexion ROM in comparison with the normal and pronated foot. This finding provides evidence that shortening of the Achilles tendon will result in limited ankle dorsiflexion ROM. Gajdosik et al. ${ }^{21)}$ highlighted that the decrease of calf muscle length, operationally defined by decreased ankle dorsiflexion ROM with the knee extended, is associated with normal aging in both men and women. A previous study by Burns and Crosbie $\left.{ }^{9}\right)$ that concluded ligament shortening, bones of the foot crowding 
Table 1. Mean rank comparisons using the Kruskal-Wallis test for range of motion, muscle length, and balance performance

\begin{tabular}{|c|c|c|c|c|c|}
\hline Variables & & & $\begin{array}{l}\text { Normal }(n=30) \\
\text { Mean rank }\end{array}$ & $\begin{array}{c}\text { Pronated }(n=30) \\
\text { Mean rank }\end{array}$ & $\begin{array}{c}\text { Supinated }(\mathrm{n}=30) \\
\text { Mean rank }\end{array}$ \\
\hline \multirow[t]{16}{*}{ ROM } & \multirow[t]{2}{*}{ Hip flexion } & Right & 42.9 & 44.4 & 49.6 \\
\hline & & Left & 40.2 & 44.9 & 51.4 \\
\hline & \multirow[t]{2}{*}{ Hip extension } & Right & 47.5 & 45.1 & 43.9 \\
\hline & & Left & 45.3 & 49.4 & 41.7 \\
\hline & \multirow[t]{2}{*}{ Knee flexion } & Right & 45.1 & 44.5 & 46.9 \\
\hline & & Left & 41.9 & 45.8 & 48.8 \\
\hline & \multirow[t]{2}{*}{ Knee extension } & Right & 42.9 & 46.15 & 47.5 \\
\hline & & Left & 44.9 & 45.15 & 46.5 \\
\hline & \multirow[t]{2}{*}{ Ankle dorsiflexion } & Right* & 55.5 & 45.7 & 35.3 \\
\hline & & Left* & 55.1 & 47.4 & 34.0 \\
\hline & \multirow[t]{2}{*}{ Ankle plantarflexion } & Right & 40.3 & 49.7 & 46.4 \\
\hline & & Left & 41.9 & 47.8 & 46.8 \\
\hline & \multirow[t]{2}{*}{ Ankle inversion } & Right & 51.6 & 43.7 & 41.2 \\
\hline & & Left & 52.6 & 46.8 & 37.1 \\
\hline & \multirow[t]{2}{*}{ Ankle eversion } & Right & 44.5 & 44.5 & 47.5 \\
\hline & & Left & 44.9 & 43.0 & 48.5 \\
\hline \multirow[t]{8}{*}{ ML } & \multirow[t]{2}{*}{ Hamstring } & Right & 40.9 & 43.8 & 51.7 \\
\hline & & Left & 42.1 & 45.0 & 49.3 \\
\hline & \multirow[t]{2}{*}{ Quadriceps } & Right & 39.37 & 43.8 & 53.4 \\
\hline & & Left & 43.03 & 44.7 & 48.8 \\
\hline & \multirow[t]{2}{*}{ Gastrocnemius } & Right & 45.5 & 49.9 & 41.1 \\
\hline & & Left & 46.7 & 51.9 & 37.9 \\
\hline & \multirow[t]{2}{*}{ Soleus } & Right & 41.9 & 49.70 & 44.9 \\
\hline & & Left & 42.6 & 53.22 & 40.7 \\
\hline \multirow[t]{2}{*}{ Balance } & \multicolumn{2}{|l|}{ FRT } & 49.3 & 41.67 & 45.6 \\
\hline & \multicolumn{2}{|l|}{ FSST } & 39.6 & 54.42 & 42.5 \\
\hline
\end{tabular}

${ }^{*} \mathrm{p}<0.05$. ROM: range of motion, ML: muscle length

together, and an increase in the longitudinal arch were brought about due to the increased activity of the muscles. In addition, the extreme tendon loads on the short Achilles tendon, for example, as well as heightening of the medial longitudinal arch may cause shortening of the plantar fascia in subjects with a supinated foot ${ }^{22}$. In this study, we measured the muscle length of the gastrocnemius and soleus separately, which differs from the methods used by Burns and Crosbie ${ }^{9)}$; according to these authors, the compliance of the calf muscles (the gastrocnemius and soleus) can be reflected by the length of the Achilles tendon and measured using the modified lunge test that is usually performed by athletes. Unfortunately, this test may not be suitable for older adults due to its potential risk of postural instability.

Interestingly, it is also apparent from the current results that the pronated foot presented with the highest mean rank for gastrocnemius and soleus muscle length when compared to a supinated and normal foot; however, the differences were not significant $(\mathrm{p}>0.05$ ). Elderly women aged more than 65 years were found to have more pronated feet, especially during ambulation, leading to a higher risk of foot problems than men $^{23)}$. Increase in gastrocnemius and soleus muscle lengths may contribute to the alteration of plantar pressure during gait, further increasing postural instability among the elderly. However, there is no clear evidence regarding changes in foot architecture that may contribute to the changes of the gastrocnemius and soleus ML with aging; accordingly, no significant differences were found between ML among different types of foot posture $(\mathrm{p}>0.05)$.

The current findings also revealed that among the pronated foot group a decreased ROM resulted in slower completion of the FSST, indicating poor balance performance. Similarly, the shorter the quadriceps ML the lower the score for the FRT. This is expected as a larger ROM and longer ML may prolong the time to complete the FSST as the foot may perform less forceful movements due to weakness or hypermobility of certain joints. According to Kawakimi et al. ${ }^{24)}$, in order for force to be exerted more effectively during a motion, the gastrocnemius and soleus muscle need to operate with limited variation in length and force.

The results of the present study also suggest a positive correlation between ankle plantar flexion and FSST which indicates that the larger the ROM (hypermobility), the longer the time to complete the FSST. Similarly, an increase in the plantarflexion as well as an increase in the muscle length of the quadriceps muscles may reduce balance performance; however, an increase 
Table 2. Spearman's rank-order correlation of ROM and ML with balance performance

\begin{tabular}{|c|c|c|c|c|c|c|}
\hline \multirow[t]{3}{*}{ Variable } & & \multirow[t]{3}{*}{ Foot posture } & \multicolumn{4}{|c|}{ Balance performance $\left(r_{s}\right)$} \\
\hline & & & \multicolumn{2}{|c|}{ FRT } & \multicolumn{2}{|c|}{ FSST } \\
\hline & & & Right limb & Left limb & Right limb & Left limb \\
\hline \multirow[t]{24}{*}{ ROM } & Hip flexion & Normal & -0.1 & -0.1 & 0.2 & 0.2 \\
\hline & & Pronated & -0.1 & -0.2 & -0.0 & -0.1 \\
\hline & & Supinated & -0.2 & -0.2 & -0.2 & -0.1 \\
\hline & Hip extension & Normal & $0.4 * *$ & $0.3^{*}$ & -0.0 & 0.0 \\
\hline & & Pronated & 0.0 & -0.1 & -0.2 & -0.1 \\
\hline & & Supinated & 0.2 & 0.1 & 0.0 & 0.2 \\
\hline & Knee flexion & Normal & 0.2 & 0.0 & 0.1 & 0.1 \\
\hline & & Pronated & 0.2 & 0.1 & -0.1 & -0.0 \\
\hline & & Supinated & -0.1 & 0.1 & 0.2 & -0.1 \\
\hline & Knee extension & Normal & $-0.3^{*}$ & $-0.3^{*}$ & 0.2 & 0.2 \\
\hline & & Pronated & -0.2 & 0.3 & $-0.3^{*}$ & -0.2 \\
\hline & & Supinated & -0.1 & 0.1 & 0.2 & 0.0 \\
\hline & Ankle dorsiflexion & Normal & -0.3 & -0.2 & 0.2 & 0.2 \\
\hline & & Pronated & 0.1 & 0.1 & $-0.5^{* *}$ & $-0.4^{*}$ \\
\hline & & Supinated & $0.4^{*}$ & $0.5^{* *}$ & -0.1 & -0.1 \\
\hline & Ankle plantarflexion & Normal & 0.1 & 0.1 & $-0.4^{*}$ & -0.2 \\
\hline & & Pronated & 0.2 & 0.3 & 0.2 & $0.4^{*}$ \\
\hline & & Supinated & $0.3^{*}$ & 0.1 & 0.1 & -0.1 \\
\hline & Ankle inversion & Normal & 0.1 & 0.2 & -0.2 & -0.1 \\
\hline & & Pronated & 0.2 & 0.1 & 0.1 & -0.1 \\
\hline & & Supinated & $0.6^{* *}$ & $0.6^{* *}$ & 0.0 & -0.1 \\
\hline & Ankle eversion & Normal & -0.1 & 0.2 & 0.1 & 0.1 \\
\hline & & Pronated & 0.2 & 0.3 & -0.0 & 0.1 \\
\hline & & Supinated & $0.4^{* *}$ & $0.5^{* *}$ & -0.2 & 0.2 \\
\hline \multirow[t]{12}{*}{ ML } & Hamstrings & Normal & -0.1 & -0.1 & $-0.4 * *$ & $-0.5 * *$ \\
\hline & & Pronated & -0.2 & -0.2 & 0.0 & 0.0 \\
\hline & & Supinated & 0.1 & 0.1 & -0.1 & -0.2 \\
\hline & Quadriceps & Normal & -0.2 & -0.2 & 0.1 & -0.0 \\
\hline & & Pronated & -0.1 & $-0.4^{*}$ & $-0.3^{*}$ & 0.2 \\
\hline & & Supinated & -0.0 & 0.1 & 0.2 & 0.0 \\
\hline & Gastrocnemius & Normal & -0.0 & 0.2 & -0.0 & 0.0 \\
\hline & & Pronated & 0.1 & 0.1 & -0.2 & -0.2 \\
\hline & & Supinated & $0.5^{* *}$ & $0.4^{*}$ & 0.2 & $0.3^{*}$ \\
\hline & Soleus & Normal & 0.1 & $0.3^{*}$ & 0.2 & 0.2 \\
\hline & & Pronated & 0.2 & 0.2 & -0.2 & -0.0 \\
\hline & & Supinated & 0.2 & 0.1 & 0.2 & 0.1 \\
\hline
\end{tabular}

${ }^{*} \mathrm{p}<0.05, * * \mathrm{p}<0.01$. ROM: range of motion, ML: muscle length

in the ankle plantar flexion may increase balance performance (FSST). The hypermobility of the pronated foot may result in flattening of the MLA; this alteration would place greater demand on the neuromuscular system to stabilize the foot and uphold a proper posture ${ }^{4)}$ leading to poor balance performance.

For the supinated foot, a smaller ROM of ankle dorsiflexion, plantar flexion, inversion, and eversion corresponded with a shorter FRT time and vice versa. Similarly, a shorter gastrocnemius ML was associated with a faster FRT time. These findings are partially consistent with a previous study ${ }^{25)}$. The current findings indicate that older adults with reduced ROM and muscle length may be at risk of poor balance performance; this may be due in part to the aging process. This is because the supinated foot may not adequately adapt to the underlying surface, and, as a result, increase the demand on the surrounding musculoskeletal structures to maintain postural stability and balance ${ }^{4)}$. Furthermore, limitation in ankle dorsiflexion may influence standing and walking balance as there is a reduction in the available range of the body's center of mass within the base of support ${ }^{25}$. 
Finally, we can conclude that a reduction in ROM, especially in the ankle joint, is more commonly found in the supinated foot. It shows that reduced ankle dorsiflexion in the supinated foot is associated with shortening of the calf muscle. Hence, these changes will eventually negatively influence balance performance. Alterations of foot posture may cause further changes to the musculoskeletal properties and joint flexibility, leading to increased risk of injuries and falls, especially among the older population. Based on this conclusion, a few recommendations can be suggested regarding healthcare practices. A thorough assessment of the foot and ankle should be included when assessing older adults being referred for fall prevention management or those with a history of falls. This is important as different types of foot postures may present with different limitations in the musculoskeletal properties. For example, an older person with a pronated foot may require strengthening exercises to certain muscles of the foot, while those with a supinated foot may need more stretching exercises in order to preserve their mobility and prevent falls.

The generalizability of these findings is subject to certain limitations. Firstly, the small sample size has prevented us from using a parametric statistical analysis. Another important limitation is that the participants of this study were only women who presented with good mobility and no painful symptoms of the lower limb or foot.Thus, the findings are less generalizable to individuals with other problems as a result of foot deformities. A final source of weakness in this study is the use of tools such as a goniometer and tape measure, which could have affected the measurements of joint range of motion and muscle length. These tools require the assessor to be highly skilled, especially in terms of their observation; in light of this, we only utilized one assessor for the score observation. A few confounding factors may have also influenced the results of the current study. These factors may include the nature of the subjects' previous job or activities, the types of footwear worn, and changes in the body weight of subjects throughout the course of their life. It is also not known whether some of the deformities were solely due to congenital or aging processes.

Further research could explore how muscle strength is affected with the different types of foot posture and whether muscle strength does influence balance performance. In addition, it would be interesting to assess the effect of fatigue on muscle function and gait kinematics in different types of foot posture.

\section{ACKNOWLEDGEMENTS}

The authors wish to thank the Ministry of Education, Malaysia for funding the research project through the Research Acculturation Grant Scheme (Ref. No. 600-RMI/RAGS 5/3 (66/2014)) as well as the Research Management Institute (RMI), Universiti Teknologi MARA (UiTM) for administrative support.

\section{REFERENCES}

1) Saltzman CL, Nawoczenski DA, Talbot KD: Measurement of the medial longitudinal arch. Arch Phys Med Rehabil, 1995, 76: 45-49. [Medline] [CrossRef]

2) Razeghi M, Batt ME: Foot type classification: a critical review of current methods. Gait Posture, 2002, 15: 282-291. [Medline] [CrossRef]

3) Scott G, Menz HB, Newcombe L: Age-related differences in foot structure and function. Gait Posture, 2007, 26: 68-75. [Medline] [CrossRef]

4) Cote KP, Brunet ME, Gansneder BM, et al.: Effects of pronated and supinated foot postures on static and dynamic postural stability. J Athl Train, 2005, 40: 41-46. [Medline]

5) Franco AH: Pes cavus and pes planus. Analyses and treatment. Phys Ther, 1987, 67: 688-694. [Medline]

6) Valmassy R: Clinical Biomechanics of the Lower Extremities, 1st ed. St Louis: Mosby, 1996.

7) Levinger P, Murley GS, Barton CJ, et al.: A comparison of foot kinematics in people with normal- and flat-arched feet using the Oxford Foot Model. Gait Posture, 2010, 32: 519-523. [Medline] [CrossRef]

8) Hertel J, Gay MR, Denegar CR: Differences in postural control during single-leg stance among healthy individuals with different foot types. J Athl Train, 2002, 37: 129-132. [Medline]

9) Burns J, Crosbie J: Weight bearing ankle dorsiflexion range of motion in idiopathic pes cavus compared to normal and pes planus feet. Foot, 2005, 15: 91-94. [CrossRef]

10) Burns J, Crosbie J, Hunt A, et al.: The effect of pes cavus on foot pain and plantar pressure. Clin Biomech (Bristol, Avon), 2005, 20: 877-882. [Medline] [CrossRef]

11) Cobb SC, Bazett-Jones DM, Joshi MN, et al.: The relationship among foot posture, core and lower extremity muscle function, and postural stability. J Athl Train, 2014, 49: 173-180. [Medline] [CrossRef]

12) Keenan AM, Redmond AC, Horton M, et al.: The Foot Posture Index: Rasch analysis of a novel, foot-specific outcome 
measure. Arch Phys Med Rehabil, 2007, 88: 88-93. [Medline] [CrossRef]

13) Redmond AC, Crane YZ, Menz HB: Normative values for the foot posture index. J Foot Ankle Res, 2008, 1: 6. [CrossRef] [Medline]

14) Clarkson HM: Musculoskeletal assessment joint range of motion and manual muscle length, 2nd ed. Pennsylvania: Lippincott Williams \& Wilkins, 2000.

15) Bandy WD, Reese BN: Joint range of motion and muscle length testing, 2nd ed. Saunders, Elsevier, 2009.

16) Duncan PW, Weiner DK, Chandler J, et al.: Functional reach: a new clinical measure of balance. J Gerontol, 1990, 45: M192-M197. [Medline] [CrossRef]

17) Takasaki K, Tanino Y, Yoneda H, et al.: Comparison of motion strategies in the functional reach test between elderly persons and young persons. J Phys Ther Sci, 2011, 23: 773-776. [CrossRef]

18) Dite W, Temple VA: A clinical test of stepping and change of direction to identify multiple falling older adults. Arch Phys Med Rehabil, 2002, 83: 1566-1571. [Medline] [CrossRef]

19) Cobb SC, Tis LL, Johnson BF, et al.: The effect of forefoot varus on postural stability. J Orthop Sports Phys Ther, 2004, 34: 79-85.

20) Menz HB, Morris ME, Lord SR: Foot and ankle characteristics associated with impaired balance and functional ability in older people. J Gerontol A Biol Sci Med Sci, 2005, 60: 1546-1552. [Medline] [CrossRef]

21) Gajdosik RL, Vander Linden DW, McNair PJ, et al.: Slow passive stretch and release characteristics of the calf muscles of older women with limited dorsiflexion range of motion. Clin Biomech (Bristol, Avon), 2004, 19: 398-406. [Medline] [CrossRef]

22) Statler TK, Tullis BL: Pes cavus. J Am Podiatr Med Assoc, 2005, 95: 42-52. [Medline] [CrossRef]

23) Hagedorn TJ, Dufour AB, Golightly YM, et al.: Factors affecting center of pressure in older adults: the Framingham Foot Study. J Foot Ankle Res, 2013, 6: 18. [Medline] [CrossRef]

24) Kawakami Y, Ichinose Y, Fukunaga T: Architectural and functional features of human triceps surae muscles during contraction. J Appl Physiol 1985, 1998, 85: 398-404. [Medline]

25) Horak FB, Henry SM, Shumway-Cook A: Postural perturbations: new insights for treatment of balance disorders. Phys Ther, 1997, 77: 517-533. [Medline] 